\title{
KULEUVEN
}

\begin{tabular}{|c|c|}
\hline Citation & $\begin{array}{l}\text { Frauenfelder, F., Müller-Staub, M. (2013), } \\
\text { Nursing interventions in inpatient psychiatry. } \\
\text { Journal of Psychiatric and Mental Health Nursing, 20(10), } 921 \text { - } 931\end{array}$ \\
\hline Archived version & $\begin{array}{l}\text { Post-print. Author manuscript: the content is virtually identical to the content } \\
\text { of the published paper, but without the final typesetting by the publisher }\end{array}$ \\
\hline Published version & http://dx.doi.org/10.1111/jpm.12040 \\
\hline Journal homepage & http://onlinelibrary.wiley.com/journal/10.1111/(ISSN)1365-2850 \\
\hline Author contact & $\begin{array}{l}\text { Theo.vanAchterberg@med.kuleuven.be } \\
\text { + } 32(0) 16373301\end{array}$ \\
\hline IR & https://lirias.kuleuven.be/cv?u=U0090873 \\
\hline
\end{tabular}

(article begins on next page) 


\section{Nursing Interventions in Inpatient Psychiatry}

Fritz Frauenfelder, MNSc, RN1

Maria Müller-Staub, PhD, MNSc, EdN, RN2

Ian Needham, PhD, MNSc, RN1

Theo van Achterberg, PhD, RN3

Correspondence address

1 Psychiatric University Hospital Zürich, Department of Research and Development, $\mathrm{CH}-8032$ Zürich, Switzerland

2 ZHAW University, $\mathrm{CH}-8401$ Winterthur \& Pflege PBS (Projects, Consulting, Research), $\mathrm{CH}-2545$ Selzach, Switzerland

3 Radboud University Nijmegen Medical Centre, Scientific Institute for Quality of Healthcare, PO Box 9101, 6500 HB Nijmegen, The Netherlands 


\section{Accessible summary}

The use of a standardized nursing language enhances nursing quality. The Nursing Interventions Classification (NIC) considers any treatment by nurses that improve patient outcomes.

The present study identifies nursing interventions in journal articles on adult psychiatric inpatient nursing care. These interventions are compared with the NIC entries to elucidate how well this classification covers the realities of nursing in inpatient psychiatric settings.

The NIC encompasses most interventions mentioned in the articles. Only a few interventions need to be added to the NIC classification or require a reorganization of the taxonomy.

\section{Abstract}

The successful application of the Nursing Interventions Classification (NIC) in inpatient psychiatry depends on whether the classification adequately describes nursing care in this setting. The present study aimed to identify nursing interventions mentioned in journal articles on psychiatric inpatient nursing care and to compare these with the labels, definitions and activities described in the NIC to elucidate how well the classification covers these interventions.

The MedLine, PsychInfo, Cochrane and CINAHL databases were searched for journal articles about nursing care in the adult inpatient setting. A qualitative content analysis approach was used to indentify nursing interventions in the articles. About $84 \%$ of the statements (terms and definitions) are encompassed by the interventions listed by the NIC. Very few interventions need to be added to the NIC classification or necessitate a reorganization of the taxonomy. Nevertheless, the further development of the NIC will promote its use in the daily work of psychiatric nurses and enhance the quality of nursing care in the inpatient setting. 


\section{Keywords:}

- nursing classifications

- Nursing Interventions Classification (NIC)

- adult inpatient psychiatric nursing care

- nursing interventions

- journal articles

- qualitative content analysis 


\section{Introduction}

The inpatient setting is only one part of the mental health care system, but clearly an important one (Aiyegbusi \& Norton, 2009). The following four reasons justify admission to an inpatient ward: the patient or relatives are unable to perform daily self-care and need help at different times during the day; the patient is in an acute personal crisis and needs services around the clock; the situation of the patient requires compulsory measures or special treatments which can only be administered in an inpatient facility, and the patient or relatives need a temporary change of setting (Sauter et al., 2011). The nursing service provides 'around the clock service' in a safe and structured environment for this group of patients (Jordan Halter, 2009) which includes three main aspects: caring, attending, and patient advocacy (Varcarolis, 2009). The nurse interacts with patients and assists them to 1) resolve the mental, emotional, and dysfunctional aspects of life crises; 2) manage and alleviate or ease painful symptoms of mental disorders; 3) improve overall functions; and 4) decrease the personal and social consequences of mental illness, including the stigma attached to mental disorders (Holoday Worret, 2008). As part of the professionalization of nursing care, there are ongoing efforts to document inpatient psychiatric nursing care with standardized languages. Documentation with standardized nursing languages enhances the continuity of care and improves analyses which support unit, organizational and national policy decisions to ensure quality and effectiveness (Keenan \& Yakel, 2005; Keenan, Tschannen \& Wesley, 2008; Müller-Staub, Needham, Odenbreit, Lavin \& van Achterberg, 2007, 2008). Just et al. (2005) recommend the use of the Nursing Interventions Classification (NIC) for the documentation of nursing interventions within a standardized documentation structure and, additionally, of the NANDA International (NANDA-I) nursing diagnoses classification and of the Nursing Outcomes Classification (NOC). 
The successful application of the Nursing Interventions Classification (NIC) in adult inpatient psychiatry depends on whether the classification adequately describes the reality of daily nursing care. No references were found in the literature to the suitability of the NIC to inpatient psychiatric nursing care. Therefore, as a first step, the present literature review considered this setting.

\section{Background}

The NIC includes three taxonomic levels: domains $(\mathrm{N}=7)$, classes $(\mathrm{N}=30)$ and interventions $(\mathrm{N}=542)$. The core of the NIC is the concept of interventions. A nursing intervention is "any treatment, based upon clinical judgment and knowledge that a nurse performs to enhance patient / client outcomes" (Bulechek 2008) encompassing direct and indirect patient care. Interventions may be aimed at individuals, families or the community and initiated by nurses, physicians and other healthcare providers (Bulechek 2008). Every intervention has a label name, a definition and a list of activities describing specific behaviors or actions in practical nursing work. Several activities are necessary to create and implement an intervention. Contrary to interventions, activities are not standardized. To implement an intervention, the corresponding activities have to be selected and, if necessary, modified or complemented with further activities to meet the needs of patients, families or communities as well as to individualize care (Bulechek 2008). With regard to the same intervention, the number of listed activities as well as the combination of activities can vary from patient to patient. It is essential that the modification or addition of activities is congruent with the corresponding definition of the intervention (Bulechek 2008).

\section{Research Questions}

The present study identified nursing actions described in journal articles in adult inpatient psychiatry. The nursing actions found in the literature were then assigned 
to the standardized nursing interventions of the Nursing Interventions Classification (NIC). The following two research questions were formulated:

- What nursing interventions are described in publications in adult inpatient psychiatry?

- Which nursing interventions identified in the publications have already been described and included in the labels and definitions of the nursing interventions of the classification of Nursing Interventions Classification $(\mathrm{NIC}) ?$

\section{Method}

\section{Search strategy}

The systematic search for articles published in nursing journals included the databases MedLine, PsychInfo, Cochrane and CINAHL. Articles meeting the following inclusion criteria were eligible:

- Published between 1993 and 2008

- Published in English or German

- Addressed to psychiatric nursing or mental health nursing

- Pertaining to an inpatient setting

- Pertaining to patients with a mental illness / mental disorder aged $18-65$ years

- Published in nursing journals or journals that explicitly address mental health nursing.

To identify the setting of the articles the following search terms were used: psychiatry' OR 'mental health care' AND 'inpatient'. To focus on articles addressing the practice of nurses, the terms above were linked with the following search terms combined in various ways and, if relevant, in singular and plural forms: 'nursing', 
'care', 'caring', 'nursing interventions, 'nursing action', 'nursing activity', 'nursing concept' 'nursing phenomena', 'actual health problem', 'potential health problem', 'acute health problem', 'chronic health problem', 'actual life process', 'potential life process', 'life process', ‘clinical judgment', 'behavior', 'perception', 'clinical judgment'. The search was stopped when no new articles were found.

\section{Methodology and Data Analysis}

The articles identified were analyzed by using a qualitative content analysis approach. This approach is suitable for analyzing and categorizing datasets from any kind of communication according to empirical or theoretical criteria (Mayring, 2010). The content analysis focused on issues related to the NIC definition of nursing intervention: "Any treatment, based upon clinical judgment and knowledge that a nurse performs to enhance patient / client outcomes" (Bulechek et al. 2008). Initially, the first author read and reread the articles. Passages mentioning nursing actions accomplished by nurses were identified. Secondly, the first author isolated each individual action and created a list of terms regarding the contexts, aims and intentions of the actions in the articles. Further, text passages specifying the actions were also isolated and added to the corresponding term. The listed actions feature two levels of abstraction. On the one hand, there are actions on the abstraction level of the standardised NIC interventions that describe treatment performed by nurses. On the other, there are actions on the level of NIC activities describing a specific behavior or intervention.

In a next step, the author compared the actions extracted from the articles with those in the Nursing Interventions Classification (NIC): Actions at the abstraction level of interventions were assigned to interventions defined by the NIC; actions on the abstraction level of activities were assigned to the list of activities of corresponding NIC interventions considering the contexts, aims and intentions 
described in the text. These identified interventions were also added to the list of interventions found on the abstraction level of interventions.

In about one-third of the isolated actions, it was not possible to assign a distinct mapping or there was a lack of an appropriate NIC intervention. For each action of this type, the first, second and third author suggested, independently of each other, an allocation to an existing or a newly created intervention. Further, the authors discussed their resulting lists term by term until a consensus was reached - again taking contexts, aims, definitions, and intentions into consideration.

\section{Results}

The initial search generated 484 abstracts. After a first review, 408 abstracts were excluded because they did not meet the inclusion criteria: most of the articles did not address inpatient settings and/or psychiatric/mental health nursing. The remaining 76 articles were studied in detail; 31 papers included statements of nursing actions; 15 publications presented qualitative surveys, nine reported quantitative studies and three a combination of both approaches. Additionally, two papers were literature reviews, one a discussion paper including vignettes and one a description of an instrument. The details about the articles in Table 1 include research questions and sample sizes. The most frequent sources of studies were Sweden (9) and the United Kingdom (8). 


\section{Table :1 Overview of papers analyzed in the study}

\begin{tabular}{|c|c|c|c|c|c|}
\hline Author & research & $\mathbf{N}$ & Context & Sample & Aim of the study \\
\hline Bowers, et al. 2000 & $\begin{array}{l}\text { quantitative / } \\
\text { quantitative }\end{array}$ & 334 & UK & $\begin{array}{l}\text { Patients / } \\
\text { Nurses }\end{array}$ & $\begin{array}{l}\text { Exploring the determinants of absconding by patients on acute } \\
\text { psychiatric wards. }\end{array}$ \\
\hline Johnson, et al. 1997 & qualitative & 12 & Canada & Patients & $\begin{array}{l}\text { Exploring the perspective, experiences, and perception of thought- } \\
\text { disordered individuals who acted aggressively. }\end{array}$ \\
\hline Tiburtius, et al. 2007 & qualitative & 12 & Sweden & Patients & $\begin{array}{l}\text { Describing patients' conceptions of how the spiritual dimension is } \\
\text { addressed in mental health care. }\end{array}$ \\
\hline Macinnes, 2006 & quantitative & 53 & UK & Patients & $\begin{array}{l}\text { Examining the significant association and relationship between self- } \\
\text { acceptance, self-esteem, and levels of psychological health (anxiety, } \\
\text { depression, psychological well-being) }\end{array}$ \\
\hline Cleary, et al. 2003 & quantitative & 46 & Australia & Patients & $\begin{array}{l}\text { Exploring of consumer discharge needs, to ascertain consumer } \\
\text { perceptions of helpful practice, to identify areas that require } \\
\text { improvement, to identify resources, to ascertain satisfaction with specific } \\
\text { aspects of services. }\end{array}$ \\
\hline Hosany, et al.2007 & quantitative & 36 & UK & Nurses & $\begin{array}{l}\text { Determining theeffect of a short training in brief Solution Focus Therapie } \\
\text { of mental health nurses on nurse-patient interaction. }\end{array}$ \\
\hline \begin{tabular}{|l|} 
Engqvist, et al. 2007 \\
\end{tabular} & qualitative & 10 & Sweden & Nurses & $\begin{array}{l}\text { Exploring strategies used by nurses in caring for women with } \\
\text { postpartum psychosis. }\end{array}$ \\
\hline Bowers, et al. 2003 & quantitative & 5 & UK & Wards & $\begin{array}{l}\text { Evaluation of the impact of an intervention to reduce absconding by } \\
\text { patients from partially locked acute psychiatric wards. }\end{array}$ \\
\hline
\end{tabular}


Nursing Interventions in Inpatient Psychiatry

\begin{tabular}{|c|c|c|c|c|c|}
\hline Spokes, et al. 2002 & qualitative & 108 & UK & Nurses & $\begin{array}{l}\text { Exploring the views of mental health nurses /assistants according staff } \\
\text { behaviours that contribute or reduce inpatient violence. }\end{array}$ \\
\hline Dood \& Wellman, 2000 & quantitative & 23 & UK & Patients & $\begin{array}{l}\text { Exploring nursing approaches using a psychological model (CBT) in the } \\
\text { management of anxiety in a setting that is unpredictable, has a high } \\
\text { turnover of patients and short lengths of stay. }\end{array}$ \\
\hline Marangos-Frost \& Wells, 2000 & qualitative & 6 & Canada & Nurses & $\begin{array}{l}\text { Exploring the situation of physical restrains experienced trough nurses, } \\
\text { to discover the nurses' feelings and thoughts and how these thoughts } \\
\text { and feelings influence nurses' decisions. }\end{array}$ \\
\hline Neilson \& Brennan, 2001 & $\begin{array}{l}\text { qualitative / } \\
\text { quantitative }\end{array}$ & 178 & unkown & $\begin{array}{ll}\text { Patient } & / \\
\text { Nurses }\end{array}$ & $\begin{array}{l}\text { Determination the use of special observations on psychiatric inpatient } \\
\text { across a range of clinical settings. }\end{array}$ \\
\hline Berg \& Hallberg, 2000 & qualitative, & 22 & Swede & Nurses & $\begin{array}{l}\text { Exploring psychiatric nurses' lived experiences of working with inpatient } \\
\text { care on a general team psychiatric ward. }\end{array}$ \\
\hline Baker, et al. 2006 & qualitative & 22 & UK & Patients & $\begin{array}{l}\text { Exploring the service users' views and experiences of the processes } \\
\text { associated with the prescription and administration of "as needed" } \\
\text { psychotropic medications in acute mental health settings. }\end{array}$ \\
\hline Carlén \& Begtsson, 2007 & qualitative, & 11 & Swede & Nurses & $\begin{array}{l}\text { Exploring the experiences of psychiatric nurses with suicidal behaviour } \\
\text { of patients within an inpatient psychiatric context. }\end{array}$ \\
\hline Haglund, et al. 2003 & qualitative & 19 & Sweden & $\begin{array}{l}\text { Patients / } \\
\text { Nurses }\end{array}$ & $\begin{array}{l}\text { Exploring the experiences of patients as well as the perception of nurses } \\
\text { with forced medication, their perceptions of alternatives and the } \\
\text { retrospectively approval of forced medication. }\end{array}$ \\
\hline Haglund, et al. 2006 & qualitative & 40 & Sweden & Nurses & $\begin{array}{l}\text { Exploring nurses' and mental health nurse assistants' perceptions of } \\
\text { advantages and disadvantages about working on a psychiatric ward with }\end{array}$ \\
\hline
\end{tabular}


Nursing Interventions in Inpatient Psychiatry

\begin{tabular}{|c|c|c|c|c|c|}
\hline & & & & & a locked entrance door. \\
\hline Wadell \& Skärsäter, 2007 & qualitative & 11 & Sweden & Nurses & $\begin{array}{l}\text { Exploring psychiatric mental health nurses' experiences of caring for } \\
\text { persons with a dual diagnosis of major depression and alcohol abuse. }\end{array}$ \\
\hline Hanglund, et al. 2004 & qualitative & 25 & Sweden & $\begin{array}{l}\text { Patients / } \\
\text { Nurses. }\end{array}$ & $\begin{array}{l}\text { Illumination of medication administration in inpatient psychiatric care, to } \\
\text { present a description of patients' and nurses' experiences of medication } \\
\text { administration, to study if experiences of coercion could be identified in } \\
\text { connection with medication administration to voluntarily admitted } \\
\text { patients. }\end{array}$ \\
\hline Wildstrand, et al. 2007 & qualitative & 6 & Sweden & Nurses & $\begin{array}{l}\text { Exploring nurses' experience caring for psychiatric patients who self- } \\
\text { harm. }\end{array}$ \\
\hline Sun, et al. 2005 & qualitative & 30 & Taiwan & $\begin{array}{l}\text { Nurses / } \\
\text { Patients }\end{array}$ & $\begin{array}{l}\text { Development of a suicide care theory that could to improve suicide } \\
\text { prevention and care. }\end{array}$ \\
\hline Kuosmanen, et al. 2006 & quantitative & 313 & Finland & Patients & $\begin{array}{l}\text { Description of psychiatric inpatients' satisfaction with the care and to } \\
\text { explore the factors associated. }\end{array}$ \\
\hline Thomas, et al. 2006 & quantitative & 228 & Australia & Patients & $\begin{array}{l}\text { Description of the reduction of the number of pro re nata (p.r.n.) } \\
\text { medications administrated in a psychiatric HDU under controlled } \\
\text { conditions. }\end{array}$ \\
\hline Curtis, et al. 2007 & quantitative & 64 & Australia & Files & $\begin{array}{l}\text { Description of the use of pro re nata (p.r.n.) psychotropic medications } \\
\text { and their association with other therapeutic interventions within acute } \\
\text { inpatient care. }\end{array}$ \\
\hline Moyle, 2003 & qualitative & 7 & Australia & Patients & To explore the patients experiences about the patient-nurse relationship. \\
\hline Bee, et al. 2006 & quantitative & 40 & UK & Nurses & Exploring the ward-based activities of both qualified and unqualified staff \\
\hline
\end{tabular}


Nursing Interventions in Inpatient Psychiatry

\begin{tabular}{|c|c|c|c|c|c|}
\hline & & & & & working in the acute inpatient setting. \\
\hline Pridding, et al. 2007 & $\begin{array}{l}\text { literatur } \\
\text { review }\end{array}$ & & & & $\begin{array}{l}\text { Reviewing the role and function of mental health nurses in dual disability } \\
\text { within acute inpatient setting. }\end{array}$ \\
\hline Szczesny \& Miller, 2003 & $\begin{array}{l}\text { discussion } \\
\text { paper } \\
\text { (vignettes) }\end{array}$ & & & & Explaining the different nursing responses to the same type of request. \\
\hline Richards, et al. 2005 & $\begin{array}{l}\text { quantitative / } \\
\text { qualitative }\end{array}$ & 228 & UK & Patients & $\begin{array}{l}\text { Exploring the effect of a specialist acute mental health nursing } \\
\text { educational program: 1) does the program have an impact on } \\
\text { documentary evidence of individualized, user-centered care? 2) Does } \\
\text { the program have an impact on service user's opinions of their care? }\end{array}$ \\
\hline Temkin \& Crotty, 2004 & $\begin{array}{l}\text { instrument } \\
\text { description }\end{array}$ & & & & $\begin{array}{l}\text { To describe the development and implementation of a new tool for } \\
\text { suicide and other monitoring for inpatient psychiatry. }\end{array}$ \\
\hline Duxbury \& Baker, 2004 & $\begin{array}{l}\text { literatur } \\
\text { review }\end{array}$ & & & & $\begin{array}{l}\text { Description of the problem in the management of anxiolytica } \\
\text { (Benzodiazeines) in the acute inpatient psychiatry and to identify an } \\
\text { agenda for potential areas of research. }\end{array}$ \\
\hline
\end{tabular}




\section{Statements listed in the Nursing Interventions Classification (NIC)}

The articles included 111 statements (terms, definitions) that could be allocated to 45 different NIC interventions, which represented 16 of 30 NIC classes and all 7 NIC domains. Table 2 lists these terms and descriptions found in the articles, as well as their assignment to the corresponding NIC interventions, classes and domains. Some interventions were listed in several NIC domains or classes, resulting in differences between the numbers of identified statements in the studies and the interventions contained in NIC domains and classes. 


\section{Table 2: Overview of the statements listed in the Classification NIC}

\begin{tabular}{|l|l|l|}
\hline $\begin{array}{l}\text { NIC Intervention / Code } \\
\text { (Domains, Classes) }\end{array}$ & $\mathbf{N}$ & Actions: Text passages specifying the actions \\
\hline $\begin{array}{l}\text { Medication Adminstration } \\
\text { 2300; } 2 \text { (H) }\end{array}$ & $\mathbf{9}$ & $\begin{array}{l}\text { Medication administration / administration of medication / the administration of prescribed medication / administration } \\
\text { of medication / to inform the patient about the main effects of medication, medication side-effects / discussions about } \\
\text { medication side-effect with service users / evaluate which medication is the most appropriate for the current situation } \\
\text { / make the best decision about whether to administer a p.r.n medication / medication administration: "Medication } \\
\text { administration is more than selecting the right medicine and administering the medicine to the right patient; it is also } \\
\text { checking on whether the medication has been ingested and monitoring desirable and undesirable effects... } \\
\text { Medication Administration was described as a ritual, initiated by selecting the right medicine, followed by giving the } \\
\text { patients the medicines, and ending by recording the administration" (Haglund et al. 2004). }\end{array}$ \\
\hline $\begin{array}{l}\text { Environmental Management: } \\
\text { Safety 6486; 4 (V) }\end{array}$ & $\mathbf{7}$ & $\begin{array}{l}\text { To create a secure environment for the patient / to establish and maintain a safe milieu / the maintenance of a safe } \\
\text { environment / removal of environmental dangers / creating a secure environment: "The nurse gives time and attention } \\
\text { to the patient, which may entail just being and sitting silently with her" (Engquvist et al. 2007) / provide a safe } \\
\text { environment: "The degree to which the psychiatric inpatient environment qualifies as safe is directly dependent on } \\
\text { factors such as the methods and tools used to monitor risk for self-harm. For example, psychiatric units have long } \\
\text { attempted to assess opportunity risk" (Temkin \& Crotty, 2004) / Protecting patients from dangerous items: "Routine } \\
\text { safety searches (once per week), irregular searches, detailed safety searches (every shift) and intimate safety } \\
\text { searches (body safety searches) (Sun et al. 2005). }\end{array}$ \\
\hline $\begin{array}{l}\text { Surveillance: Safety 6654; } \\
\text { (V) }\end{array}$ & $\mathbf{7}$ & $\begin{array}{l}\text { The performance and documentation of special observations / monitoring patients on suicide or homicide precautions } \\
\text { / }\end{array}$ \\
\hline
\end{tabular}




\begin{tabular}{|c|c|c|}
\hline & & $\begin{array}{l}\text { to monitor suicidal and other high-risk behavior / to monitor risk for self-harm / special observation: "The formal } \\
\text { assignation of nursing staff to maintain a clearly defined degree of observation or supervision over a patient who is } \\
\text { assessed as representing some degree of risk to self and/or others on a single or multiple variables" (Neilson \& } \\
\text { Brennan, 2001) / monitoring and supervision: "Close supervision during which the nurses monitored acute patients, } \\
\text { who were assessed as being at high suicide risk, every } 5 \text { min. In addition, a close-circuit television monitor was used } \\
\text { to keep a watchful eye on patients who had strong ideas of suicide" (Sun et al. 2005) / Suicidal precaution: "...a } \\
\text { member of staff be within arms reach and have the patient in sight with no barriers between...A staff member must } \\
\text { visually check a patient's status every } 15 \text { minutes... the patient is observed hourly" (Temkin \& Crotty, 2004). }\end{array}$ \\
\hline $\begin{array}{l}\text { Case Management 7320; } 6 \\
(\mathrm{Y}), 7 \text { (c) }\end{array}$ & 6 & $\begin{array}{l}\text { Service co-ordination / coordinating cross-system care / as advocates for people with intellectual disability / advocacy } \\
\text { for individuals and family / connecting the patient to the care team: "In this way, the nurse acts as a link between the } \\
\text { patient and the midwife by exhibiting close cooperation for the mother and baby's sake" (Engquvist et al. 2007) / } \\
\text { collect and collate patients' information: "That is, the information sharing from nurses, doctors, patients, patients' } \\
\text { families, record and a form of assessment of risk to suicide" (Sun et al. 2005). }\end{array}$ \\
\hline $\begin{array}{l}\text { Chemical Restraint 6430; } 4 \\
\text { (V) }\end{array}$ & 6 & $\begin{array}{l}\text { Documentation of the administration of p.r.n medication and the reasons for them / administration of p.r.n. medication } \\
\text { / administration of "as needed" or pro re nata psychotropic medication / the administration of "as required" medication } \\
\text { / to provide service users with information and treatment choices about "as needed" medication / forced medication: } \\
\text {..."can be needed to protect patients against themselves or to protect other persons and/or to restore a patient's } \\
\text { capacity to make autonomous decisions. Forced medication procedures are generally perceived to be clinically } \\
\text { necessary options, albeit violating individuals' bodies and thus autonomy" (Haglund et al. 2003). }\end{array}$ \\
\hline $\begin{array}{l}\text { Discharge Planning } 7370 ; 6 \\
\text { (Y) }\end{array}$ & 6 & $\begin{array}{l}\text { Information to assist with discharge / explanation of the discharge arrangements / involvement of the patient in } \\
\text { discharge planning / written information about discharge arrangements / provision of a written discharge plan and } \\
\text { information package to consumers / to prepare patient for discharge included increased contact with consumer }\end{array}$ \\
\hline
\end{tabular}




\begin{tabular}{|c|c|c|}
\hline & & \\
\hline Presence 5340; 3 (R) & 5 & $\begin{array}{l}\text { To communicate openness and acceptance of the patients feelings and life situation / Mental and emotional care: "... } \\
\text { this aspect of care gave nurses exceptional opportunities to 'be there' with suicidal patients - in their humanity, } \\
\text { physically, emotionally, in their presence and in time" (Sun et al. 2005). / Being with the patient: "The nurses spent } \\
\text { time listening to the patients and assisting them to talk about their fears, anxieties and problems (Moyle, 2003)". "The } \\
\text { constant presence of nursing staff at the bedside, especially before or after unfamiliar procedures such as } \\
\text { electroconvulsive therapy, as an ideal form of being nurtured that offered them comfort and reassurance" (Moyle, } \\
\text { 2003). / Being continuously present: "The nurses said that it is important to be physically present and close to the } \\
\text { patient, to sit beside her, give physical touch and by putting her arms around her so that the patient can see and feel } \\
\text { the presence of the nurse. Psychological presence is to show interest in the patient and to give her full attention, even } \\
\text { through periods of silence" (Engquvist et al. 2007) / being there: Daily caregiving was described as "being there" for } \\
\text { the patient, focusing the presence, and that meant being with as well as doing things for and with the patients" (Berg } \\
\text { \& Hallberg, 2000). }\end{array}$ \\
\hline Surveillance 6650; 4 (V) & 4 & servation / vigilant observations / to control patients / clinical observations of patient behavior and appearance. \\
\hline $\begin{array}{l}\text { Teaching: Disease Process } \\
5602 ; 3 \text { (S) }\end{array}$ & 4 & $\begin{array}{l}\text { Information transfer to patients about treatment and illness / to inform the patient about the illness or associated } \\
\text { problems experienced / to inform the patient about dealing with practical aspects of mental illness, and recognizing } \\
\text { mental health deterioration / Informing the patient and her relatives about Post-Perinatale Psychosis: "One important } \\
\text { aspect of communication is imparting information to the patient and her relatives. When the patient is transferred or } \\
\text { admitted to the psychiatric outpatient care, the nurse generally gives information about the illness to the woman's } \\
\text { partner" (Engquvist et al. 2007). }\end{array}$ \\
\hline Admission Care 7310; $6(\mathrm{Y})$ & 3 & erviewing order to carry out the holistic assessment; / Information about hospital on admission / initial assessments \\
\hline Physical Restraint 6580; 1 & 3 & $t$ / coercive measures e.g. seclusion, restraint and restrictions on leaving the ward / the \\
\hline
\end{tabular}




\begin{tabular}{|c|c|c|}
\hline$(\mathrm{C}), 4(\mathrm{~V})$ & & $\begin{array}{l}\text { use of physical restraints: "Nurses described restraint use as arising from a situation in which patients, others persons } \\
\text { and/or the unit were perceived to be at risk of imminent harm. They felt the need to use restraints to manage the } \\
\text { potential for harm" (Marrangos-Frost \& Wells, 2000). }\end{array}$ \\
\hline Risk Identification 6610; 4 (V) & 3 & rocess of risk assessment / risk assessments / assess opportunity risk. \\
\hline $\begin{array}{l}\text { Substance Use } \text { Treatment } \\
4510 ; 3(0)\end{array}$ & 3 & $\begin{array}{l}\text { Making the Alcohol Problem Clear to the Patient: Open discussion of the patient's alcohol problem was a prerequisite } \\
\text { for care and treatment (Wadell, K. \& Skärsäter, I. 2007) / Informing and Motivating: The nurses considered it } \\
\text { important that they help the patient gain insight into his or her alcohol abuse, motivate him or her to stop drinking, and } \\
\text { encourage the patient to comply with the treatment. (Wadell, K. \& Skärsäter, I. 2007) / Establishing a Social Network } \\
\text { as a Basis for Continued Treatment: The nurses mapped out the patient's professional social network, from the } \\
\text { hospital as well as the community, after which the patient had the opportunity to discuss and plan together with the } \\
\text { persons in that network, leading to a feasible care plan (Wadell, K. \& Skärsäter, I. 2007) }\end{array}$ \\
\hline $\begin{array}{l}\text { Suicide Prevention 6340; } 4 \\
(\mathrm{U}, \mathrm{V})\end{array}$ & 3 & $\begin{array}{l}\text { To involve the patient in care planning / recognize the warning signals of suicide / protecting patients' safety: "The } \\
\text { nurses carried out four key nursing activities to protect the patients' safety: a 'no-suicide' contract, increased safety } \\
\text { measures in the bathroom, maintaining overall safety and ensuring minimalism" (Sun et al. 2005). }\end{array}$ \\
\hline $\begin{array}{l}\text { Teaching: Procedure / } \\
\text { Treatment } 5618 ; 3(\mathrm{~S})\end{array}$ & 3 & $\begin{array}{l}\text { Information transfer to patients about treatment and illness / explanations given to you by the nurses about your care } \\
\text { / to inform the patient about treatment. }\end{array}$ \\
\hline Documentation 7920; 6 (b) & 2 & $\begin{array}{l}\text { Administrative tasks (such as ward and patient-based paperwork). / Administration: "Patient based (writhing/up-dating } \\
\text { patient dates, ward round prep / follow-up diary completion / following-up, admission / discharge procedures, risk } \\
\text { assessment procedure, sorting finance / accommodation)" (Bee et al. 2006). }\end{array}$ \\
\hline $\begin{array}{l}\text { Environmental Management } \\
6480 ; 4(\mathrm{~V})\end{array}$ & 2 & $\begin{array}{l}\text { Reduction of environmental influences (noise, social interaction) / to restrict the patient to fewer stimuli: "... that she } \\
\text { [Patient] is less disturbed by others, except for the presence of the nurse. Other restrictions that make the patient feel } \\
\text { secure are for her to stay in her room, eat her meals there and have all activities during the day in isolation. This is }\end{array}$ \\
\hline
\end{tabular}




\begin{tabular}{|c|c|c|}
\hline & & $\begin{array}{l}\text { performed to protect the patient from potential shameful behavior, which she might later regret, and feel embarrassed } \\
\text { by" (Engquvist et al. 2007). }\end{array}$ \\
\hline $\begin{array}{l}\text { Health Care Information } \\
\text { Exchange } 7969 ; 6 \text { (b) }\end{array}$ & 2 & $\begin{array}{l}\text { Collaboration with the delivery ward / communications: "External: social worker, CMHTS, transfers referrals, drug } \\
\text { representatives, other agencies; internal: colleagues, ward managers, doctors/consultations, OT; meeting } \\
\text { unspecified" (Bee et al. 2006). }\end{array}$ \\
\hline Hope Inspiration 5310; $3(\mathrm{R})$ & 2 & $\begin{array}{l}\text { Giving confirmation and hope: "... a great deal of time is spent communicating with the patient. By so doing, the nurse } \\
\text { affirms the patient's experience as a woman, mother and human being. The nurse reminds the patient that she is a } \\
\text { mother and this is her child and she is the best one to care for her child" (Engquvist et al. 2007) / Instilling hope: } \\
\text { "encouraging or teaching positive thinking, promoting self-confidence, valuing patients as people, and teaching } \\
\text { problem-solving" (Sun et al. 2005). }\end{array}$ \\
\hline $\begin{array}{l}\text { Patient Rights } \text { Protection } \\
7460 ; 6(Y)\end{array}$ & 2 & Information about rights / to inform the patient about rights awareness. \\
\hline Seclusion 6630; $4(\mathrm{~V})$ & 2 & The use of physical seclusion / seclusion ( includig time out). \\
\hline $\begin{array}{l}\text { Teaching: } \quad \text { Prescribed } \\
\text { Medication 5616; } 2(\mathrm{H}), 3(\mathrm{~S})\end{array}$ & 2 & Education of inpatients about their medication / service user education about medication side effects. \\
\hline $\begin{array}{l}\text { Vital Signs Monitoring 6680; } 4 \\
\text { (V) }\end{array}$ & 2 & Monitoring blood pressure / monitoring pulse and respiratory rate. \\
\hline active Listening 4920; $3(\mathrm{Q})$ & 1 & Listening. \\
\hline Anxiety Reduction 5820; 3 (T) & 1 & Management of anxiety symptoms in patient admitted. \\
\hline $\begin{array}{l}\text { Behavior Management 4350; } \\
3(\mathrm{O})\end{array}$ & 1 & To create a structured environment. \\
\hline Behavior Modification: Social & 1 & Teaching patients to talk directly about their anger to the persons involved. \\
\hline
\end{tabular}




\begin{tabular}{|c|c|c|}
\hline Skills 4362; 3 ( O) & & \\
\hline $\begin{array}{l}\text { Cognitive Restructuring 4700; } \\
3(P)\end{array}$ & 1 & $\begin{array}{l}\text { Reconnect the patient to reality: "The nurse frequently speaks with the patient trying to reconnect her to reality when } \\
\text { psychotic. The nurse attempts to have the patient understand what is going on here and now, hopefully, bringing her } \\
\text { back to reality" (Engquvist et al. 2007). }\end{array}$ \\
\hline $\begin{array}{l}\text { Complex } \quad \text { Relationship } \\
\text { Building 5000; } 3(Q)\end{array}$ & 1 & Negotiating boundaries of closeness-distance. \\
\hline Counseling 5240; $3(\mathrm{R})$ & 1 & Counselling. \\
\hline $\begin{array}{l}\text { Crisis Intervention 6160; } 3 \\
(\mathrm{R}), 4(\mathrm{U})\end{array}$ & 1 & Preventive strategies in crisis situations: "Isolation, use of the protection room and restraint" (Sun et al. 2005). \\
\hline $\begin{array}{l}\text { Decision - Making Support } \\
\text { 5250; } 3(\mathrm{R})\end{array}$ & 1 & $\begin{array}{l}\text { Consultation in relation to decision-making: ...the respondents [patient] were consulted about discharge decisions } \\
\text { when in hospital, ... were consulted in relations to decisions about medication and ... were consulted in regard to } \\
\text { decisions about treatment (Cleary et al. 2003). }\end{array}$ \\
\hline Distraction 5900; $3(\mathrm{~T})$ & 1 & Distraction. \\
\hline $\begin{array}{l}\text { Elopement Management } \\
6470 ; 4(\mathrm{~V})\end{array}$ & 1 & $\begin{array}{l}\text { The Anti-Absconding Package:" 1) Use of a signing in and out book for patients. 2) Careful and supportive breaking } \\
\text { of bad news to patients. 3) Post ward incident debriefing of patients. 4) Multidisciplinary review. 5) Identification of } \\
\text { patients at high risk of absconding. 5) Targeted nursing time daily for those high absconding risk patients. 6) } \\
\text { Facilitated social contact for those at high risk of absconding" (Bowers et al. 2003). }\end{array}$ \\
\hline Family Support 7140; $5(\mathrm{X})$ & 1 & Education for individuals and family. \\
\hline $\begin{array}{l}\text { Health } \\
\text { Guidance7400; } 6(\mathrm{Y})\end{array}$ & 1 & To inform the patient about peer support groups. \\
\hline Limit Setting 4380; $3(0)$ & 1 & $\begin{array}{l}\text { Setting limits: setting limits in relation to patients to avoid splitting of staff and self-harm of the patient (Wilstrand et } \\
\text { al.2007) }\end{array}$ \\
\hline
\end{tabular}




\begin{tabular}{|c|c|c|}
\hline $\begin{array}{l}\text { Parent Education: Infant } \\
5568 ; 3(\mathrm{~S}), 5(\mathrm{Z})\end{array}$ & 1 & $\begin{array}{l}\text { Need to address the relationship between the woman and her child: "By the nurse setting an example when changing } \\
\text { diapers and holding and talking with the baby, she becomes a model for the patient of how to care for her baby and } \\
\text { helps her to feel more secure in caring for her child" (Engquvist et al. 2007). }\end{array}$ \\
\hline $\begin{array}{l}\text { Parent Education: } \\
\text { Childrearing Family 5566; } 3 \\
\text { (S), } 5 \text { (Z) }\end{array}$ & 1 & $\begin{array}{l}\text { Need to address the relationship between the woman and her child: "By the nurse setting an example when changing } \\
\text { diapers and holding and talking with the baby, she becomes a model for the patient of how to care for her baby and } \\
\text { helps her to feel more secure in caring for her child. The nurse can improve the relationship" (Engquvist et al. 2007). }\end{array}$ \\
\hline $\begin{array}{l}\text { Relaxation Therapie } 6040 ; 3 \\
\text { (T) }\end{array}$ & 1 & Relaxation. \\
\hline $\begin{array}{l}\text { Security Enhancement 5380; } \\
3(\mathrm{R})\end{array}$ & 1 & $\begin{array}{l}\text { Satisfying basic needs and providing a sense of security: "The nurse assists in extracting excess breast milk from the } \\
\text { woman, helps with hygiene and makes sure that the patient looks presentable. The nurse is responsible for the } \\
\text { patient's meals and brings it to the patient in her room. The nurse is involved in helping with the shopping and other } \\
\text { tasks" "...to protect the patient from potential shameful behavior, which she might later regret, and fell embarrassed } \\
\text { by" (Engquvist et al. 2007). }\end{array}$ \\
\hline Shift Report 8140; 6 (b) & 1 & Professional communications (meetings and hand-overs). \\
\hline Spiritual Support 5420; 3 (R) & 1 & The assistance to address their spiritual needs. \\
\hline $\begin{array}{l}\text { Support } \quad \text { System } \\
\text { Enhancement 5440; } 3(\mathrm{R})\end{array}$ & 1 & To build a network of support. \\
\hline $\begin{array}{l}\text { Transport: Interfacility } 7890 ; 6 \\
\text { (a) }\end{array}$ & 1 & To transfer patient between wards. \\
\hline Touch 5460; 3 (R) & 1 & $\begin{array}{l}\text { Nurturing embrace: ... When a nurse embraced them [patient] the experienced relief from their emotional and sensual } \\
\text { needs, feelings of being safe in a childlike world, and feeling free from fears and distractions of the depressed mind" } \\
\text { (Moyle, 2003). }\end{array}$ \\
\hline
\end{tabular}




\section{Domains}

Most interventions were reflected in the domains "Safety: Care that supports protection against harm" (N: 44), "Behavioral: Care that supports psychosocial functioning and facilitates lifestyle changes" (N: 37) and "Health System: Care that supports effective use of the health care delivery system" (N:24). The domains "Physiological: Complex: Care that supports homeostatic regulation" (N: 11), "Community: Care that supports the health of the community" $(\mathrm{N}: 6)$ as well as the domains "Physiological: Basic: Care that supports physical functioning" (N: 3) and "Family: Care that supports the family" (N: 3) were also represented.

\section{Classes}

In-depth analysis showed variations of incidence at the level of classes in contrast to domains. The domains with the most nominations did not necessarily contain the classes with the most frequently listed interventions. In some cases, the incidence of classes varied with the incidence of the domains. The class "Risk Management: Intervention to initiate risk-reduction activities and continue monitoring risks over time" (N: 40) was far more frequently identified than other classes. This class is involved in the most frequently named domain and responsible for its rank in the order of precedence. The second most frequently identified class was "Health System Mediation: Intervention to facilitate the interface between patient/family and the health care system" $(\mathrm{N}: 18)$. This class is listed in the domain "Health System" that contained the third most frequent references. The class "Coping Assistance: Interventions to assist another to build on own strengths, to adapt to a change in function, or achieve a higher level of function" ( $\mathrm{N}: 13)$ presented the third most frequently identified class. Because there were five other classes, e.g. "Patient Education: Interventions to facilitate learning" (N: $11 ; 4^{\text {th }}$ position) and "Behavior Therapy: Intervention to reinforce or promote desirable behaviors or alter undesirable behaviors" ( $\mathrm{N}: 6 ; 5^{\text {th }}$ position), the 
corresponding domain "Behavioral" appeared as the second most frequently identified domain.

The class "Drug Management: Intervention to facilitate desired effects of pharmacological agents" (N: 11) - the fourth most frequently identified class beside "Patient Education" - was the only class that registered statements from articles in the domain of "Physiological: Complex", which is the largest domain in NIC. Beside the class "Behavior Therapy" mentioned above, there was another class in $5^{\text {th }}$ position: "Community Health Promotion: Interventions that promote the health of the whole community". The remaining 23 classes contained less than five or no mentions.

Interventions

The NIC intervention "Medication Administration" describes nursing tasks related to medication; nine actions in the articles were analyzed as describing such interventions. Seven actions found in the articles were allocated to the NIC interventions "Environmental Management: Safety" and "Surveillance: Safety". The main focus of both interventions is safety, on the one hand by monitoring and manipulating the physical environment, and on the other by collecting and analyzing information about the patient and his or her environment. Six actions were related to each of the three NIC interventions: "Case Management" that coordinates care and advocates for individuals or groups across settings; "Chemical Restraint" that describes the handling of psychotropic agents to control extreme behavior; and Discharge Planning" that prepares the patient to move on from a particular setting. Five actions fell into the category of the NIC interventions "Presence". This intervention characterizes the physical and psychological presence of nurses in the care of patients. The NIC interventions "Surveillance" and "Teaching: Disease Process" both reflect four actions. The first intervention describes the acquisition and handling of patient data for clinical decision-making, 
the second intervention delineates the procedure of teaching patients to understand information relating to their disease.

There were six NIC interventions that were addressed by three actions each: "Admission Care", "Physical Restraint", and "Risk Identification", as well as

"Substance Use Treatment", "Suicide Prevention", and "Teaching: Procedure / Treatment". "Admission Care" is a description of the regular care at the moment of entry into a care facility. "Physical Restraint" addresses the procedure of mechanical restraining, and "Risk Identification" analyzes potential risk factors for a patient or a group. The intervention "Substance Use Treatment" reflects the physical and psychosocial care of patients who have problems with alcohol or drugs, the intervention "Suicide Prevention" describes the nursing procedure to prevent suicide, and the intervention "Teaching: Procedure / Treatment" is defined as the procedure of teaching patients to understand the steps of the treatment. The remaining $30 \mathrm{NIC}$ interventions contained only one or two actions. Their contents were very different and there was no obvious pattern that explained the nature of these interventions.

\section{Statements unable to be mapped to NIC}

Twenty-two actions did not fit existing NIC interventions due to their meaning and descriptions and required the creation of additional NIC interventions, or the revision of some structures in the NIC taxonomy. These actions are grouped into eight interventions by consensus of the authors considering context, aims and intention described in articles (Table 3). 


\begin{tabular}{|l|l|l|}
\hline $\begin{array}{l}\text { NIC Intervention / Code } \\
\text { (Domaines, Classes) }\end{array}$ & $\mathbf{N}$ & Actions: Text passages specifying the actions \\
\hline Care Planning 6 (Y) & $\mathbf{5}$ & $\begin{array}{l}\text { The individualization of care plans / to involve the patient in care planning / to monitor patient progress in response to } \\
\text { treatment / mapping out the situation together with the patient: "The nurses collected information in order to gain a } \\
\text { holistic view of the patient's life and tried to be sensitive about the meaning of what the patient said. It was essential } \\
\text { for the patient to narrate his or her own history and describe the kind of help that was most needed" (Wadell \& } \\
\text { Skärsäter, 2007). / Involving in drawing up their own care plans: "This process should not only include service users } \\
\text { reading and signing their care plans together with staff, or service users discussing the progress of this care to } \\
\text { determine whether or not the care plan is meeting their needs, but also service users actually devising care plans in } \\
\text { partnership with staff" (Richards et al. 2005). }\end{array}$ \\
\hline Therapy 3 (?) & $\mathbf{5}$ & $\begin{array}{l}\text { Cognitive behavioral therapy / therapeutic interventions such as CBT / identification and provision of relevant } \\
\text { therapeutic activities / solution-focused therapy: "The focus of discussion is on solutions (not problems); the future } \\
\text { (not the past) and on what's going well (rather than what's gone wrong)" (Hosany et al. 2007). / Cognitive Behavior } \\
\text { Therapy: "Nurses are increasingly using cognitive behavior therapy as an intervention for psychological problems } \\
\text { attached to a variety of clinical conditions" (Macinnes, 2006). }\end{array}$ \\
\hline De-escalation; 4 (V) & $\mathbf{4}$ & $\begin{array}{l}\text { Talking with an aggressive patient / intervening in a patient-patient interaction / verbal de-escalation / de-escalation: } \\
\text { "P.r.n. medication should not be the first line of action, but is the treatment strategy when other less invasive } \\
\text { interventions such as de-escalation, talking, or separation from the group are unsuccessful. De-escalation skills refer } \\
\text { to a combination of understanding environmental reasons for aggression, risk assessment, and verbal and non-verbal }\end{array}$ \\
\hline
\end{tabular}




\begin{tabular}{|c|c|c|}
\hline & & strategies for calming a situation" (Curtis et al. 2007). \\
\hline Partnership; $3(\mathrm{Q})$ & 4 & $\begin{array}{l}\text { Negotiating boundaries of closeness-distance / partnership with the patient: "a partnership between the patient and } \\
\text { nurse is crucial to reach a beneficial therapeutic result. This partnership facilitates the patient's participation in } \\
\text { planning care and treatment such as decisions about privileges she might receive and whether she may go for walks } \\
\text { alone" (Engqvist et al 2007) / Creating a relationship based on trust: "The nurses believed that the creation of a } \\
\text { trusting relationship with the patient and ensuring that the patient has confidence in the care received was most } \\
\text { important". "The nurses were aware that if they gave the patients time, built up their confidence, and entered into a } \\
\text { trusting relationship with them, their patients would become more open and talk about their drinking habits" (Wadell \& } \\
\text { Skärsäter, 2007) / developing a working relationship with the patient in everyday care giving: "The texts revealed two } \\
\text { main approaches in the nurse - patient relationship. The first and dominating approach emphasized the nurse as an } \\
\text { "expert" knowing what was the best solution to the patients' problems or needs. The other approach emphasized the } \\
\text { nurse as a "Collaborator" on the basis of mutual co-operation in exploring the patients' problems and needs" (Berg \& } \\
\text { Hallberg, 2000). }\end{array}$ \\
\hline Body Search; 4 (V) & 1 & Intimate safety searches (body safety searches). \\
\hline Administration; 6 (b) & 1 & $\begin{array}{l}\text { Administration: "Ward based (general administration / checking post, staff training \& supervision, staff rotation / } \\
\text { collaboration" (Bee et al. 2006). }\end{array}$ \\
\hline Self Advocacy; $3(\mathrm{Q})$ & 1 & Promote self advocacy and independent advocacy (developing personal autonomy). \\
\hline $\begin{array}{l}\text { Risk Identification: } \\
\text { Aggression; } 4(\mathrm{~V})\end{array}$ & 1 & To make a judgment about a patient's potential to cause serious bodily harm to self or others. \\
\hline
\end{tabular}


Five actions represented each of the most frequently identified interventions that focus on planning nursing care or therapies performed by nurses. The second most frequently identified interventions were each constituted by four actions that focus on de-escalation or partnership. The remaining interventions (Body Search, Administration, Self Advocacy or Risk Identification: Aggression) were represented by one action each.

\section{Discussion}

Various authors describe the content of nursing in psychiatric inpatient settings. Sauter et al. (2011) define the aims of psychiatric inpatient settings as a) prevention of danger, b) reduction of psychiatric symptoms, and c) improvement of subjective conditions and general stabilization in the context of the mental illness. The safe and structured environment of a psychiatric inpatient setting is essential for patients in need of protection from suicidal ideation, aggressive impulses, medication adjustment and monitoring, crisis stabilization, substance abuse detoxification, and behavior modification (Jordan Halter, 2009). Rungapadiachy, Madill \& Gough (2004) identified mental health nurses as: an administrator who organizes, documents and links patients with other members of the heath care team; an advocate of psychological interventions who spends time and builds relationships with patients as well as performs structured therapeutic programs (e.g. cognitive behavior therapy); an agent of physical interventions who observes and performs physical care (e.g. physical hygiene, nutritional needs); as well as an administrator of drugs and a teacher. Psychiatric mental health nurses assist patients in resolving mental, emotional and dysfunctional aspects of life crises. Nurses also manage and alleviate distressing symptoms of mental disorders, improve overall functioning, and decrease the consequences of mental illness (Holoday Worret, 2008). 
Despite the fact that the results of the current literature search reflect all domains of the Nursing Interventions Classification (NIC), nursing care in inpatient psychiatric settings is represented by three main focuses. Around $75 \%$ of the identified interventions in the NIC domains are listed in the domains "Safety" (support against harm), "Behavioral" (supporting psychosocial functioning as well as facilitating lifestyle changes), and "Health System" (mediating between the patient and the health system).

Within the domain "Safety", the class "Risk Management" contains the greatest number of interventions identified in the literature (40 statements). Based on these results, the work of psychiatric nurses in inpatient settings seems dominated by risk-reducing and risk-monitoring interventions. Buchanan-Barker \& Barker (2005) interpreted the growing needs for safety as a main topic (of societies, the political mainstream as well as the mental health services) in the $21^{\text {st }}$ century, influencing the medical paradigm within mental health care. However, the contemporary practices of mental health nurses are dominated by risk management activities, especially the "bureaucratic process of observation" (Buchanan-Barker \& Barker, 2005). As an alternative to the concept of "Risk Management", the authors suggest a concept of 'bridging' on the basis of interpersonal relationships and the power of caring.

The interventions in the domain "Behavioral" were distributed into different NIC classes. Two classes are particularly noteworthy: "Coping Assistance" (13 statements) and "Patient Education" (11 statements). The first class describes interventions of assistance in developing personal strengths, to adapt to functional changes and/or to achieve higher functional levels. Koivisto et al. (2004) describe experiences of patients with psychoses who received the help of nurses in inpatient settings. Generally, patients experience nursing care as helpful but unstructured. On the one hand, nursing interventions should protect patients from vulnerability so that the individual feels safe, understood, respected, and trusted 
and thus becomes more self-conscious and maintains his or her integrity. On the other, nursing care should assist in the restructuring and empowering of the self to cope in daily life. Conversations with primary nurses are considered by many patients to be the most important caring activities (Koivisto et al, 2004). The class "Patient Education" contains interventions to facilitate learning. An earlier study has shown that patient education has to be a systematic and planned process, employing different educational methods and taking the interaction between patient and nurse into consideration (Hätönen et al, 2010).

The class "Health System Mediation" - integrated into the domain "Health System" - is the second most frequently represented class (18 nominations). The class contains interventions such as "Admission Care", "Discharge Planning", "Case Management" and "Patient Rights Protection". It summarizes interventions that facilitate the interface between patients, their families and the health care system. These interventions seem particularly important because psychiatric inpatient settings are environments over which patients have little control (Roger \& Gray 2009)

The class "Drug Management" (11 statements) contains interventions to facilitate desired effects of medical treatments. Effective medication management practices empower the patient to make informed treatment decisions and to closely monitor the effects of medicine (Gray \& Deborah, 2009). In the current study, the class is represented by the interventions "Medical Administration" and "Teaching: Prescribed Medication". The intervention "Medical Administration" is noteworthy as it is the most frequently cited nursing intervention in the current study. Tentative interpretations of this finding could include the legal necessity to meticulously document the administration of medication or the predominance of the medical paradigm in psychiatric nursing.

Although the greatest number of identified intervention terms and definitions are already contained in the NIC, the significance, meaning and content of some 
interventions could not be mapped to the classification. Several actions describe different steps and approaches of planning nursing care focusing on individualization, on interactions between nurse and patient and on the process of monitoring. Although the NIC intervention "Admission Care" contains elements of statements found in the articles, it fails to define the comprehensive and accurate process of nursing care planning that seems to be a continual process throughout the whole period of hospitalization and not only at admission. Therefore the intervention "Care Planning" was suggested to accommodate the identified actions. Because the intervention "Care Planning" supports the effective use of nursing care, it should probably be listed in the domain "Health System". Further, since the intervention refers to an interactive action between patient and nurse we propose its allocation to the class "Health System Mediation".

This study revealed actions indicating different therapy methods performed by nurses in inpatient psychiatry. The NIC taxonomy contains two classes into which therapeutic nursing interventions in inpatient psychiatry can be allocated: "Behavior Therapy", which contains interventions to modify behavior, and "Cognitive Therapy", which contains interventions to support cognitive functioning. The design of the NIC taxonomy allows neither interventions with other therapeutic orientations (e.g. solution therapy) nor interventions with a combination of both approaches (e.g. cognitive behavior therapy) to be established. To ensure a comprehensive intervention classification system, it seems necessary to reorganize the current NIC taxonomy at the level of classes within the domain "Behavioral" to include further therapeutic approaches.

Several results found in the articles indicate the existence of nursing activities aiming to defuse foreseeable conflicts. The main focus of these activities is on deescalating strategies to prevent different forms of aggression escalation and dangerous moments. These activities reduce the risks of harm and help control 
circumstances. Pavalonis (2008) describes de-escalation skills as effective techniques in interpersonal relationships that are essential for mental health nurses. Further, Varcarolis \& Alverez (2009) mentioned that nurses have to be well-trained in de-escalation techniques to deal with violent situations and individuals. Because these nursing actions support safety, the suggested intervention "De-escalation" should be integrated into the domain "Safety" and into the class "Risk Management".

The analysis of the articles highlighted actions that describe the importance of and different approaches to developing a partnership or working relationship with patients. In contrast to the NIC intervention "Complex Relationship Building”, which addresses the promotion of insight and behavioral changes, the actions found address successful interaction with patients, acting as a basis for nursing care and going beyond the necessity to promote insight and behavioral changes. The suggested intervention "Partnership" contains steps and approaches to establish a common basis for successful interaction between nurses and patients. The intervention "Partnership" requires time, professional skills and human resources and should be integrated into the domain "Behavioral" and the class "Communication Enhancement".

The following interventions - reflecting nursing actions that are time consuming, contain several working steps, and have a beginning and an end - were identified in the literature by one statement only. Although their database seems to be marginal, the suggested interventions "Body Search" and "Administration" as well as "Self Advocacy" and "Risk Identification: Aggression" are well-established practical nursing activities in adult inpatient psychiatry but inadequately reflected in the literature.

The intervention "Body Search" is planned to be listed under the domain "Safety" and added to the class "Risk Management". This intervention entails nurses searching for objects or substances that are not allowed in a certain area because 
they are dangerous for others or for the patient him/herself. Based on the descriptions found, the intervention "Administration" contains common and regularly performed ward-based administrative actions unlinked to other interventions or to the NIC intervention "Documentation". In this sense, "administration" was used to describe documentation and is therefore part of communication. For this reason, this new intervention should be listed under the domain "Health System" and the class "Information Management". The suggested intervention "Self Advocacy" includes nursing actions that develop the personal autonomy of patients. The content of the suggested intervention "Risk Identification: Aggression" seems to be different from the content of the existing intervention "Surveillance: Safety". The definition of "Risk Identification: Aggression" as a separate intervention, focusing on the identification of risk factors, seems to be more appropriate.

\section{Limitations}

Some limitations of this study should be mentioned. The search strategy was limited to German and English papers listed in the databases MedLine, PsychInfo, Cochrane and CINAHL, and explored articles published in English only. For this reason, language bias cannot be ruled out. The search strategy addressed publications listed in databases, while other written documents were excluded from the analyses. There is thus a need to encompass other languages and other kinds of publications (e.g. articles from related disciplines) as well as to extend research on alternative methodologies and samples (e.g. documentation analyses, interviews) regarding psychiatric nursing interventions.

The determination process of nursing interventions implies some room for interpretation, on the one hand by a lack of standardized language or precise description of actions in articles, and on the other in the course of assignment of actions at the abstraction level of activities to corresponding NIC interventions. The 
consideration of contexts, aims and intentions of the identified actions in the original text limited the room for interpretation and entailed a decisive focus that allowed a precise assignment to interventions.

The identification of some psychiatric nursing interventions was based on one study only. Although these nursing interventions are established in practice and often used in the daily routine of psychiatric nursing, they are seldom described in the literature. Therefore, further research is needed to verify the present results. Additional studies are important to define psychiatric inpatient nursing care and to differentiate individual nursing interventions and activities.

\section{Conclusion}

This study demonstrates that nursing care in adult inpatient psychiatry settings is based on well-defined tasks and activities included in the Nursing Interventions Classification (NIC). About $83 \%$ of the statements (terms and definitions) found in the articles are contained by the classification. Nevertheless, there is still a necessity to specify and communicate some psychiatric nursing interventions. The results of this study provide a basis for further research on nursing interventions improving patient outcomes. The design of this study included a literature review and mapping procedures. It demonstrates that the NIC classification contains most activities and interventions described in the literature. Only a few interventions need to be added to the NIC classification or demand a reorganization of the taxonomy. Closing this gap would strengthen the knowledge base of mental health nursing as well as the application of the NIC classification in psychiatric nursing practice. It is essential that nurses understand why and through which activities they perform interventions. 


\section{References}

Aiyegbusi, A. Norton, K. (2009) Modern milieus: psychiatric inpatient treatment in the twenty-first century. In: The Art and Science of Mental Health Nursing (eds. Norman, I. \& Ryrie, I.) $2^{\text {th }}$ edn. pp. 260 - 282, Open University Press, Berkshire

Baker, J.A., Lovell, K., Easton, K. \& Harris, N. (2006) Service users' experiences of 'as needed' psychotropic medications in acute mental healthcare settings. Journal of Advanced Nursing, 56 (4), $354-362$

Buchanan-Barker, P. \& Barker, P. (2005) Observation: the original sin of mental health nursing? Journal of Psychiatric and Mental Health Nursing, 12, 541-549

Bulechek, G.M., Butcher, H.K. \& McCloskey Dochterman, J. (2008) Nursing Interventions Classification (NIC), $5^{\text {th }}$ edn. Mosby Elsevier, St. Louise Missouri

Bee, P.E., Richards, D.A., Loftus, S.J., Baker, J. A., Bailey, L., Lovell, K., Woods, P. \& Cox, D. (2006) Mapping nursing activity in acute inpatient mental healthcare settings. Journal of Mental Health, 15 (2), 217 - 226

Berg, A., \& Hallberg, R. (2000) Psychiatric nurses' lived experiences of working with inpatient care on a general team psychiatric ward. Journal of Psychiatric and Mental Health Nursing, 7, $323-333$

Bowers, L., Jarrett, M., Clark, N., Kiyimba, F. \& McFarlane, L. (2000) Determinants of absconding by patients on acute psychiatric wards. Journal of Advanced Nursing, 32 (3), $644-649$

Bowers, L., Alexander, J., \& Baskell, C. (2003) A trial of an anti-absconding intervention in acute psychiatric wards. Journal of Psychiatric and Mental Health Nursing, 10, $410-416$

Carlén, P. \& Bengtsson, A. (2007) Suicidal patients as experienced by psychiatric nurses in inpatient care. International Journal of Mental Health Nursing, 16, 257 265 
Cleary, M., Horsfall, J. \& Hunt, G.E. (2003) Consumer feedback on nursing care and discharge planning. Journal of Advanced Nursing, 42 (3), 269 - 277

Curtis, L., Baker, J.A. \& Reid, A.R. (2007) Exploration of therapeutic interventions that accompany the administration of p.r.n. ('as required') psychotropic medication within acute mental health settings: A retrospective study. International Journal of Mental Health Nursing, 16, $318-326$

Dood, H. \& Wellman, N. (2000) Staff development, anxiety and relaxation techniques: a pilot study in an acute psychiatric inpatient setting. Journal of Psychiatric and Mental Health Nursing, 7, 443 - 448

Duxbury, J.A. \& Baker, J. (2004) The use and nursing management of benzodiazepines in acute, mental health inpatient care: a discussion. Journal of Psychiatric and Mental Health Nursing, 11, 622 - 667

Engqvist, I. Nilsson, A. Nilsson, K. \& Sjörström, B. (2007) Strategies in caring for women with postpartum psychosis - an interview study with psychiatric nurses. Journal of Clinical Nursing, 16, 1333 - 1342

Gray R. \& Robson, D. (2009) Medication management. In: Mental Health Nursing, An Evidence-Based Approach (eds Newell, R. \& Gournay, K.), pp. 109 - 128. Churchill Livingstone Elsevier, Philadelphia, PA.

Hätönen, H. Suhonen, R. Warro, H. Pitkänen, A. \&Välimäki, M. (2010) Patients' perceptions of patient education on psychiatric inpatient wards: a qualitative study. Journal of Psychiatric and Mental Health Nursing, 2010, 17, 335-341

Holoday Worret, P.A. (2008) Principles of Psychiatric Nursing: Theory and Practice. In: Psychiatric Mental Health Nursing (eds Fortinash, K.M. \& Holoday Worret, P.A.), pp. 1 - 19. Mosby Elsevier, St. Louis, Missouri

Haglund, K., von Knorring, L. \& von Essen, L. (2003) Forced medication in psychiatric care: patient experiences and nurse perception. Journal of Psychiatric and Mental Health Nursing, 10, $65-72$ 
Haglund, K., von Essen, L., Knorring L. \& Sidenvall, B. (2004) Medication administration in inpatient psychiatric care - get control and leave control. Journal of Psychiatric and Mental Health Nursing, 11, 229 - 234

Haglund, K., von Knorring, L. \& von Essen, L. (2006) Psychiatric wards with locked doors - advantages and disadvantages according to nurses and mental health nurse assistants. Journal of Clinical Nursing, 15, $387-394$

Holoday Worret P. (2008) Principles of Psychiatric Nursing: Theory and Practice. In: Psychiatric Mental Health Nursing eds. Fortinash K.M. \& Holoday Worret P.A.). Mosby Elsevier, St. Louis Missouri.

Hosany, Z. Wellman, N. \& Lowe, T. (2007) Fostering a culture of engagement: a pilot study of the outcomes of training mental health nurses working in two UK acute admission units in brief solution-focused therapy techniques. Journal of Psychiatric and Mental Health Nursing, 14, 688 - 695

Johnson, B., Martin, M.-L., Guha, M. \& Montgomery, P. (1997) The experience of thought-disordered individuals preceding an aggressive incident. Journal of Psychiatric and Mental Health Nursing, 4, 213 - 220

Jordan Halter, M (2009) Setting for Psychiatric Care. In: Essentials of Psychiatric Mental Health Nursing, A Communication Approach to Evidence-Based Care (eds Varcarolis, E.M. \& Halter, J.M.), pp. 535 - 546. Saunders Elsevier, St. Louis, Missouri.

Just A., Arnold A., Busch N., et al. (2005) Ordnungssystem zur Abbildung des Pflegeprozesses im eletronischen Patientendossier - Eine Empfehlung zuhanden der Pflegedienst-Kommission der Gesundheitsdirektion des Kantons Zürich. In, Zürich.

Keenan, G., Tschannen, D., \& Wesley, M. L. (2008). Standardized nursing teminologies can transform practice. Jona, 38(3), 103-106.

Keenan, G., \& Yakel, E. (2005). Promoting safe nursing care by bringing visibility to the disciplinary aspects of interdisciplinary care. [Evaluation Studies]. AMIA. Annual Symposium proceedings / AMIA Symposium. AMIA Symposium, 385-389. 
Koivisto, K. Janhonen, S. \& Väisänen, L. (2004) Patients' experiences of being helped in an inpatient setting. Journal of Psychiatric and Mental Health Nursing, $11,268-275$

Kuosmanen, L., Hätönen, H., Jyrkinen, R.A., Katajisto, J. \& Välimäki, M. (2006) Patient satisfaction with psychiatric inpatient care. Journal of Advanced Nursing, 55 (6), $655-663$

Macines, D. L.(2006) Self-Esteem and -acceptance: an examination into their relationship and their effect on psychological health. Journal of Psychiatric and Mental Health Nursing, 13, $483-489$

Marangos-Frost, S. \& Wells, D. (2000) Psychiatric nurses' thoughts and feelings about restraint use: a decision dilemma. Journal of Advanced Nursing, 31 (2), 362 $-369$

Mayring, P. (2010) Qualitative Inhaltsanalyse, $11^{\text {th }}$ edn. Belz Verlag, Weinheim

Moyle, W. (2003) Nurse-patient relationship: A dichotomy of expectations. International Journal of Mental Health Nursing, 12, 103 - 109

Müller-Staub, M., Needham, I., Odenbreit, M., Lavin, M. A., \& van Achterberg, T. (2007). Improved quality of nursing documentation: Results of a nursing diagnoses, interventions and outcomes implementation study. International Journal of Nursing Terminologies and Classifications, 18(1), 5-17.

Müller-Staub, M., Needham, I., Odenbreit, M., Lavin, M. A., \& van Achterberg, T. (2008). Implementing nursing diagnostics effectively: cluster randomized trial. Journal of Advanced Nursing, 63(3), 291-301.

Neilson, P. \& Brennan, W. (2001) The use of special observations: a audit within a psychiatric unit. Journal of Psychiatric and Mental Health Nursing, 8, $147-155$

Pavalonis, D. (2008) Schizophrenia and Other Psychotic Disorders. In: Psychiatric Mental Health Nursing (eds Fortinash, K.M. \& Holoday Worret, P.A.), pp. 249 283. Mosby Elsevier, St. Louis, Missouri 
Pridding, A., Watkins, D. \& Happell, B. (2007) Mental Health Nursing Roles and Functions in Acute Inpatient Units: Caring for People with Intellectual Disability and Mental Health problems - A Literature Review. The International Journal of Psychiatric Nursing Research, 12 ( 2), 1459 - 1470

Richards, D., Bee, P., Loftus, S., Baker, J., Bailey, L. \& Lovell, K. (2005) Specialist education intervention for acute inpatient mental health nursing staff: service user view and effects on nursing quality. Journal of Advanced Nursing, 51 (6), 634 644

Roger, P. \& Gray, R. (2009) Inpatient Nursing. In Mental Health Nursing (eds. Newell, R. \& Gournay, K.) pp. $151-169,2^{\text {th }}$ edn., K. Churchill Livingstone Elsevier, Edinburgh

Rungapadiachy, D. M., Madill, A. \& Gough, B (2004) Mental health student nurses' perception of the role of the mental. Journal of Psychiatric and Mental Health Nursing, 11, 714-724

Sauter, D., Abderhalden, C., Needham, I. \& Wolff, S. (2011) Lehrbuch Psychiatrische Pflege, $3^{\text {th }}$ edn. Verlag Hans Huber, Bern

Spokes, K., Bond, K., Lowe, T., Jones, J., Illingworth, P., Brimblecombe, N. \& Wellman, N. (2002) HOVIS - The Hertfordshire / Oxfordshire Violent Incident Study. Journal of Psychiatric and Mental Health Nursing, 9, 199 - 209

Sun, F.K., Long, A., Boore, J. \& Tsao, L.I. (2005) Nursing people who are suicidal on psychiatric wards in Taiwan: action / interaction strategies. Journal of Psychiatric and Mental Health Nursing, 12, 275 - 282

Szczesny, S. \& Miller, M. (2003) PRN Medication Use in Inpatient. Psychiatry. Journal of Psychosocial Nursing, 41 (1), 16 - 21

Thomas, B., Jones, M., Johns, P. \& Trauer, T. (2006) P.r.n. medication use in a psychiatric high-dependency unit following the introduction of a nurse-led activity programme. International Journal of Mental Health Nursing, 15, 266 - 271 
Tiburtius, K. \& Arvidsson, B. (2007) Patients' conceptions of how the spiritual dimension is addressed in mental health care: a qualitative study. Journal of Advanced Nursing, 57 (6), $597-604$

Tremkin, T.M. \& Crotty, M. (2004) Suicide and Other Risk Monitoring in Inpatient Psychiatry. Journal of the American psychiatric Nurses Association, 10 (2), 73 - 80

Wadell, K. \& Skärsäter, I. (2007) Nurses' experiences of caring for patients with a dual diagnosis of depression and alcohol abuse in a general psychiatric setting. Issues in Mental Health Nursing, 28, 1125 - 1140

Wildstrand, C., Lindgren, B.-M., Gilje, F. \& Olofsson, B. (2007) Being burdened and balancing boundaries: a qualitative study of nurses' experiences caring for patients who self-harm. Journal of Psychiatric and Mental Health Nursing, 14, 72 - 78

Varcarolis E.M. \& Alverez, C. (2009) Anger and Aggression. In: Essentials of Psychiatric Mental Health Nursing, A Communication Approach to Evidence-Based Care (eds Varcarolis, E.M. \& Halter, J.M.), pp. 424 - 441. Saunders Elsevier, St. Louis, Missouri.

Varcarolis E.M. (2009) Practicing the Science and Art of Psychiatric Nursing. In: Essentials of Psychiatric Mental Health Nursing, A Communication Approach to Evidence-Based Care (eds Varcarolis, E.M. \& Halter, J.M.), pp. 2 - 10. Saunders Elsevier, St. Louis, Missouri. 